\title{
Considerações sobre Causalidade, Escolha e Liberdade em Leibniz
}

\author{
M ark Julian $\mathrm{R}$ ichter $\mathrm{C}$ ass \\ Universidade Federal de São Carlos
}

resumo Duas formulações oferecidas por Leibniz de seu princípio de causalidade são examinadas, e a incompatibilidade, segundo Leibniz, do princípio com a possibilidade de causas indiferentes com respeito a seus efeitos é considerada. Acompanhamos 0 desenvolvimento de sua teoria da escolha a partir de suas teses sobre causalidade e indiferença. Por fim, procuramos explicar por que Leibniz sustentava que sua teoria de escolha não exclui a liberdade.

palavras-chave liberdade - contingência - causalidade - razão - necessidade

A teoria da escolha de Leibniz baseia-se no seu princípio de causalidade. A presentaremos esse princípio distinguindo duas versões do mesmo, coisa que o próprio Leibniz não faz. M ostraremos que sua teoria de escolha segue apenas de uma dessas versões - aquela propriamente chamada de prinápio de raz ão suficiente. Segundo Leibniz, uma escolha feita entre alternativas desejadas revela a preferência pelo objeto escolhido: quem escolhe não pode estar indiferente diante das alternativas, ainda que todas sejam desejadas. $\mathrm{O}$ u por outra, segundo Leibniz a indiferença resultaria num impasse, na escolha de nenhuma das alternativas. No entanto, iremos argumentar que a possibilidade de que a indiferença seja uma etapa no proces so de escolha não é excluída pelo princípio de razão suficiente; este somente nega que uma escolha seja imediatamente precedida por indiferença em relação a alternativas. A lgumas razões oferecidas por Leibniz em apoio a seu princípio de razão suficiente são então consideradas: sua autoevidência e o princípio de contradição. Por fim, explicaremos brevemente como sua teoria de liberdade humana foi forjada em consonância com seu princípio de razão suficiente e sua teoria de escolha.

R ecebido em julho de 2005. A ceito em setembro de 2005.

doispontos, Curitiba, São C arlos, vol. 2, n. 1, p.123-133, outubro, 2005 


\section{4}

\section{Os Princípios de Causalidade}

Leibniz oferece pelo menos duas versões de seu princípio de causalidade. As versões que tenho em mente são as seguintes:

PR 1. "N ada existe sem uma razão, ou, não há efeito sem uma causa" 1 .

PR 2. "N enhum fato pode ser verdadeiro ou existente, nem algum enunciado correto, sem que haja uma razão suficiente para ser assim e não de outro modo"2.

Para facilitar comparação, PR 2 pode ser expressa como segue:

PR 2. N ada existe sem uma razão suficiente, ou não há efeito sem uma causa suficiente.

Entendo por 'uma razão pela qual algo é assim e não de outro modo' sua razão suficiente.

Leibniz pensava que PR 1 e PR 2 são equivalentes; é evidente que ele identifica 'razão' com 'razão suficiente'. N o entanto, embora PR 2 clara mente implique PR 1, essa, à primeira vista, pode ser verdadeira e PR 2 falsa: talvez não sejam equivalentes. Como a análise de PR 2 envolve PR 1, basta examinarmos PR 2.

PR 2 não afirma apenas que cada evento (ou efeito) tem uma causa, mas que a causa de um evento é suficiente para sua ocorrência. PR 2 nega que (a) existam eventos que não são causados (e é isso que PR 1 também nega), e que (b) as causas completas de alguns eventos (todos os fatores causais relevantes para a sua ocorrência) sejam insuficientes. De acordo com a condição (b), é falso que da causa completa de qualquer evento se possa seguir algum outro evento. Ela nega, por exemplo, que a causa completa do número nove ter sido obtido com um par de dados poderia ter resultado no número sete; e que uma bola, depois de bater na armação, ceteris paribus, poderia então ter caído dentro da cesta em vez de fora dela. A primeira condição, (a), nega que algo possa mudar ou aparecer sem uma razão ou história causal - que, por exemplo, um par de dados poderia aparecer 'do nada' sobre a mesa, e que uma bola parada poderia começar a se mover sem que alguma força tivesse agido sobre ela.

PR 2 também é conhecido como o princípio metafísico de determinismo. Assim, a tese contrária pode ser entendida como asseverando ou a existência de eventos não causados (por exemplo, dados que aparecem 'do nada', ou uma bola em movimento que muda de direção sem que alguma 
força tenha agido sobre ela), ou a existência de causas completas mas insuficientes para seus efeitos?3.

\section{Razão Suficiente, Preferência e Escolha}

Segundo Leibniz, uma conseqüência de PR 2 é que a totalidade dos fatores causais responsáveis pela produção de um efeito (a causa completa ou total do efeito) não pode ser indiferente à ocorrência do efeito; PR 2 nega que a causa completa de um efeito poderia ter resultado em algo diferente (algum outro efeito). Em outras palavras, Leibniz não admite existência de causas indiferentes em relação a seus efeitos. Inclusive, ele nega que a indiferença possa imediatamente preceder escolhas, ou que suas causas completas sejam indiferentes em relação às escol has feitast. Ele entende que uma escolha entre al ternativas requer uma razão (suficiente), “... quer dizer, uma inclinação maior para aquilo que de fato foi escolhido, que pode vir de argumentos bons ou ruins, mas também de paixões, hábitos, disposições dos órgãos e da mente, impressões externas, maior ou menor atenção etc" 5 . Leibniz insiste, portanto, que escolhas feitas revelam ou expressam tais juízos, inclinações e preferênciasో.

Leibniz procura na balança de Arquimedes apoio para sua posição acerca da indiferença. Poucas sentenças antes da última citada, ele escreve: "A rquimedes assume como certo que a balança não se inclinará numa direção mais que na outra, quando tudo estiver igual em ambos os lados; e do mesmo modo todos os que argumentam sobre a moral e a política, tendo em vista descobertas sobre ações humanas, usam implicitamente 0 mesmo fundamento, 0 de que há sempre uma razão ou causa que inclina a vontade [a uma escolha]" 7 . Segundo Leibniz, a indiferença não pode ser a causa completa de uma escolha: a indiferença só levará a um impasse. 0 asno de Buridan morreria de fome, se não preferisse um monte ao outro; se não morre, sua preferência é estabelecida. U ma escolha entre alternativas desejadas implica que a balança se inclinou numa direção; para Leibniz, não pode haver equilíbrio quando escolhas são feitas.

Seguindo sua sugestão, vale a pena desenvolver a teoria de escolha de Leibniz a partir da teoria da balança de A rquimedes. U ma balança cujos pesos estão eqüidistantes do fulcro (uma balança simétrica) se inclinará 


\section{6}

para um lado, se os pesos não forem iguais; e uma balança simétrica estará em equilíbrio, se os pesos forem iguais. Essa balança seria descrita por Leibniz como segue: a existência de diferentes pesos é uma razão suficiente para que uma balança simétrica se incline para um lado; a existência de pesos iguais é uma razão suficiente para o equilíbrio (para a balança não se inclinar para um lado). A ssim, a teoria de Leibniz acerca da escolha pode ser enunciada da seguinte maneira: escolhe-se entre duas alternativas, se se prefere uma à outra (a alternativa preferida é escolhida); não haverá uma escolha entre duas alternativas em apreço, se não houver preferência por nenhuma das duas (ou seja, se o observador for indiferente quanto a ambas). N outras palavras, a preferência é uma razão suficiente para uma escolha, e, a indiferença é uma razão suficiente para um impasse, para que nenhuma escolha seja feita. D o mesmo modo que pesos iguais eqüidistantes determinam equilíbrio, para Leibniz a indiferença acerca de alternativas determina um verdadeiro atoleiro. Isso não contradiz o que foi dito anteriormente - que, de acordo com o princípio da razão suficiente, a causa total para a ocorrência de um efeito não Ihe pode ser indiferente. 0 que esse princípio nega é a possibilidade de a causa total de um efeito (uma escolha ou um impasse) não determiná-lo; noutras palavras, o princípio nega que a causa total de um impasse poderia ter resultado numa escolha, e que a causa total de uma escolha poderia ter resultado num impasse ou na escolha de algo diferente.

Vale repetir essa distinção entre indiferença como causa total de uma escolha (essa possibilidade é negada por Leibniz) e como causa total de um impasse. Segundo o princípio de razão suficiente, não há desvios no caminho de uma causa total a seu efeito - não há outros destinos ou outras escolhas possíveis (a causa total não é indiferente no sentido de que se pode largar no meio 0 caminho da causa total a seu efeito). M as se porventura 0 destino for uma encruzilhada, e nos sentirmos indiferentes com relação a qual dos caminhos devemos seguir, não iremos adiante, até que algo faça uma diferença.

Podemos oferecer alguma razão, diferente de PR 2, para a recusa da existência de causas indiferentes em relação a seus efeitos? Sem dúvida é possível que às vezes escolhamos entre alternativas igualmente desejadas, ou entre alternativas que sentimos que satiffariam igualmente nossos desejos (possível, no sentido de que a suposição não implica uma 
contradição). N ão é inconcebível que escolhamos nessas condições, que rompamos sem hesitar o impasse, simplesmente porque queremos satisfa zer nossos desejos (ou porque queremos chegar a algum lugar) ${ }^{8}$. Leibniz acredita que raramente enfrentamos tal situação, se é que a enfrentamos: "Se a indiferença completa é necessária para a liberdade, quase nunca haverá uma escolha livre, porque acredito que raramente acontece que tudo seja igual em ambos os lados. Porque, ainda que as razões fossem porventura iguais, as paixões não 0 seriam. $\mathrm{N}$ ão acredito que exemplos podem ser citados em que a vontade escolhe - ou seja, em que um impasse é rompido pelo simples ato de escolher -, porque sempre há uma razão para a escolha de uma alternativa em vez da outra" ${ }^{9}$. I sso parece uma recusa empírica, contingente e incerta da indiferença: muda a modalidade expressa al hures contra a indiferença. $M$ as ainda que raramente "tudo seja igual em ambos os lados", o princípio de razão suficiente - em particular, sua cláusula (b) - não pode ser verdadeiro.

Seria insensato negar que a indiferença seja uma etapa no processo de deliberação e escolha quando alternativas são pesadas e não se dá preferência a nenhuma. Quando avaliamos alternativas, freqüentemente passamos de nenhum sentimento claro de preferência, de nenhuma inclinação, à seleção de uma das alternativas. Leibniz diria que, em algum momento antes da escolha, algum fator imprevisto (talvez inconsciente) fez uma diferença e rompeu o impasse; e, assim, a escolha foi determina da. Seguramente, para Leibniz o próprio ato de eleger uma alternativa não é um fator causal da escolha (somente D eus é uma causa sui). Portanto, Leibniz somente nega que indiferença preceda imediatamente 0 ato de escolha. Ao que parece, essa seria a única conseqüência testável de sua teoria de escolha (ou de uma teoria indeterminista da escolha) ${ }^{10}$.

A principal evidência oferecida por Leibniz para sua teoria de escolha (se ignoramos seu momento de introspecção) é o princípio de razão suficiente. A questão da plausibilidade da teoria, portanto, nos remete à da plausibilidade do princípio. N a Teodicéia $\S 169$, Leibniz parece acreditar que o princípio é analítico, que sua negação implica uma contradição; ou seja, que o princípio de contradição fundamenta PR 2. Segue seu argumento. O ntem ou era verdadeiro ou era falso que escreveria (ou escolheria escrever) esta sentença hoje. Se negarmos isso, negamos o princípio de contradição (pelo qual o que implica uma contradição é falso), assim 


\section{8}

como sua lei derivada do meio excluído. $\mathrm{N}$ ão pode ser falso que escreveria aquela sentença (porque de fato a escrevi), então era verdadeiro ontem; portanto, o fato de que a escrevi hoje já estava determinado ontem ${ }^{11}$. Há alguma falha nesse argumento? Suponhamos que acabo de obter o número nove com um par de dados. Antes de jogar, ou era verdadeiro ou era falso que o nove seria obtido; estamos diante de uma tautologia, então não há do que reclamar. M as é possível que o resultado não fosse fisicamente determinado antes que os dados parassem de rolar - que a causa completa de o número nove ter sido obtido fosse indiferente em relação a esse resultado. Em outras palavras, assumimos que o valor de verdade "U m nove será obtido" não poderia ser decidido, mesmo por uma mente onisciente (ou em princípio), antes que os dados parassem de rolar - que seu valor de verdade não foi determinado antes disso (há uma hora era possível que eu não jogasse agora, e, se jogasse, que o resultado fosse um número diferente). Voltemos ao exemplo de Leibniz: embora ontem fosse ou verdadeiro ou falso que decidiria escrever aquela sentença hoje, ontem não era necessário que as coisas se encaminhassem como de fato se encaminharam. É evidente que isso só seria possível se PR 2 fosse falso. Mas essa suposição não requer a negação do princípio de contradição; portanto, esse princípio não implica PR 2.

Por chamá-lo de "princípio", talvez Leibniz entendesse que PR 2 é um axioma auto-evidente - uma proposição que não requer prova, porque, embora seja negada sem contradição, não a negamos sem profunda repulsa. Seguramente, esse não é o único sentido de "princípio" para Leibniz: seu princípio de identidade de indiscerníveis é derivado do seu princípio de razão suficiente (portanto o princípio de identidade dos indiscerníveis não é um axioma), e seu princípio de harmonia pré-esta belecida não seria considerado auto-evidente nem pela imaginação mais fértil. É plausível que ele também chame de "princípios" leis universais e metafísicas que governam as coisas desde a C riação. Esse é um uso legítimo, embora incomum, de "princípio". Seja isso como for, sugeri que a cláusula (b) de PR 2 não é auto-evidente - que não há contra-senso em pensar que a causa completa de uma escolha, por exemplo, seja indiferente em relação à alternativa escolhida. Embora talvez nem sempre pensemos que causas completas são suficientes para seus efeitos, isso não significa que supomos existirem eventos, incluindo escolhas, não causados 
(que pensamos que PR 1 ou PR 2(a) é falso). PR 1 é auto-evidente? Posso imaginar que pessoas escolhem sem motivos, que os dados apareceram 'do nada' sobre a mesa, e que uma bola em movimento mudou de direção sem qualquer razão mundana (sem bater numa trave, por exemplo). No entanto, ainda que essas possibilidades fossem descritas sem contradição, me inclino a aceitar PR 1 como verdadeiro.

\section{Razão Suficiente e Escolha Livre}

Finalmente, trataremos do conceito de liberdade segundo Leibniz. M as, antes, vale sublinhar que não há inconsistência em negar PR 2 e liberdade humana: talvez todos os atos humanos (em especial aqueles que somos tentados de descrever como livres) sejam determinados e somente os resultados de jogos de dados sejam indeterminados (mas não 0 ato em si de jogá-los). Portanto, a recusa de PR 2 não é suficiente para liberdade. A ssim, nos dirigimos ao problema formulado por Leibniz: a indiferença completa é necessária para liberdade?

Sua caracterização da liberdade humana se baseia no princípio de razão suficiente; assim, se temos razões para recusar o princípio sem fazêlo a contragosto, talvez isso seja uma razão para não aceitar sem mais aquela caracterização. 0 que Leibniz diz sobre liberdade humana? 0 fereceremos aqui apenas um esboço. Segundo Leibniz, aquelas ações de A dão que descrevemos como livres são livres porque têm como única fonte a naturez a de A dão. A 'natureza de A dão' é a idéia divina (ou seja, que Deus tem) e completa de Adão (todas as propriedades ou "percepções" de A dão, incluindo suas escolhas, devidamente ordenadas), que D eus decidiu criar segundo seu propósito: a sucessão das percepções reais de A dão (suas propriedades) está em exato acordo com a idéia divina de A dão antes da C riação. Portanto, há uma razão suficiente para todas as coisas criadas (o propósito de Deus), e uma razão suficiente para cada propriedade de cada coisa criada (a idéia completa de cada criatura).

No entanto, segundo Leibniz, as seguintes condições (analíticas) da liberdade não foram contraditas: a existência de A dão não é necessária, porque o poder de D eus não é incompatível com uma escolha diferente; as escolhas deA dão não são necessárias (A dão não tinha que existir, nem, 
portanto, suas propriedades: é possível que as escolhas de Adão não fossem feitas, e não o seriam caso ele não existisse); e, uma vez que D eus decidiu criar A dão (o único tipo de decisão livre, no sentido de que Ele poderia ter escolhido não criá-lo), todas as propriedades de Adão fluem exclusivamente da sua natureza - por isso, às vezes Leibniz diz que as propriedades das coisas (incluindo as escolhas de Adão) são "espontâneas" 12. Segundo Leibniz, A dão não agiria livremente se fosse coagido; em nenhum momento ele foi forçado a agir contra sua natureza e vontade. Evidentemente, não é suficiente para que um ato seja corretamente descrito como 'livre' que seu agente esteja livre de coerção: pessoas em estado de coma normalmente não estão sendo coagidas, e não agem livremente. Para Leibniz, escolhas livres também requerem inteligência e deliberação ${ }^{13}$. Inteligência é a capacidade de perceber fins diferentes (ou alternativas) e meios alternativos de al cançá los; e deliberação é a capacidade de escolher um fim e de avaliar os diferentes meios para alcançá-lo. Mas, argumenta Leibniz com base no princípio de razão suficiente, conhecimento e deliberação sobre fins e meios determinam resultados únicos: um único fim, e um meio.

Segundo Leibniz, portanto, se A dão escolheu espontaneamente, com inteligência e deliberação, ele agiu livremente. Sua decisão de comer não é livre, no entanto, no sentido que ele poderia, naquele momento, ter recusado a oferta; era inevitável, segundo Leibniz, que ele comesse, dado a idéia completa de Adão ou aquilo que precedeu sua escolha (por exemplo, a oferta e sua deliberação 14). Ao que parece, uma resposta à pergunta, "As pessoas às vezes escolhem livremente?", depende de uma resposta à pergunta, "O que entendemos por 'escolha livre'?". I magino que não há uma resposta unânime quanto às condições necessárias de liberdade. Eis uma razão, um tanto decepcionante, para afirmar que "indiferença completa" não é necessária para a liberdade: alguns (Leibniz entre estes) não aceitam que seja necessária para uma caracterização adequada de liberdade.

\section{Em suma}

A questão da existência de causas indiferentes em relação a seus efeitos não só diz respeito à liberdade e à escolha de fins e meios. Algumas 
máquinas muito simples produzem efeitos diferentes a partir de causas aparentemente indiferentes 15 - a partir de operações que são percebidas como idênticas' ${ }^{16}$. A indiferença causal também não é universalmente negada em genética ou física atômica; nem em economia, jogos de azar e teologia. E a indiferença causal é consistente com PR 1. É possível que eventos e escolhas tenham histórias causais, ainda que não sejam decisivas (ainda que não sejam suficientes para seus efeitos). E isso vale para dados lançados, os olhos azuis de João e a escolha de A dão.

Talvez Leibniz desse como sua principal razão para PR 2 a natureza do conhecimento de D eus e sua capacidade de explicar. Se a causa total de um evento fosse indiferente no sentido definido (se sua causa completa pudesse resultar em algo diferente), uma explicação verdadeira, dedutiva e causal não poderia ser oferecida, nem por uma mente onisciente, para 0 efeito assim como foi caracterizado. Se a causa total do número nove ter sido obtido é realmente indiferente, ninguém seria capaz de explicar por que o número nove foi obtido, em vez de algum outro número (por exemplo, sete). Talvez a melhor explicação causal (ou, por impossível, a explicação completa) de um evento não nos dissesse por que foi "assim e não de outro modo"17. M as não deixaria de ser uma explicação, e talvez uma resposta verdadeira a uma pergunta do tipo "Por quê?" (Por que os olhos de João são azuis? Porque seu bisavô tinha olhos azuis etc). Talvez alguns digam que tais explicações não são satiffatórias ou científicas; mas isso é paradoxal, se não há outro tipo de explicação correta. N o entanto, se há eventos não causados (ou seja, se PR 1 for falso), nenhuma explicação correta pode ser dada para tais eventos.

É possível que uma das razões que levou Leibniz a aceitar PR 2 seja 0 fato de que ele tenha confundido PR 2 com PR 1: PR 1 é mais plausível. Em seu crédito, outros filósofos eminentes também não fizeram qualquer distinção 18 .

1 PAR KIN SO N, 1973, p. 88.

2 M onadologia §32. LEIBN IZ, 1998, p. 272.

3 Suficiência causal não deve ser confundida com implicação material: dado que os eventose circunstâncias descritos por $P$ constituem a causa completa mas insuficiente do evento designado por Q , P materialmente implica Q, se essas proposições são verdadeiras. 


\section{2}

4 Com respeito a escolhas entre alternativas, a indiferença não deve ser entendida como implicando apatia ou a ausência de desejo.

5 'A letter on freedom' (c. 1689). PAR KIN SO N, 1973, p. 113.

${ }^{6}$ A expressão "preferência revelada" foi cunhada pelo economista Paul Samuelson. D oravante, o termo "preferência" deve ser entendido como indicando todos os motivos para uma escoIha. $E$ assumo que as seguintes proposições são equivalentes: "A dão prefere ou $A$ a $B$ ou $B$ a A" e "A dão não é indiferente entre A e B".

7 "Archimedes takes it for granted that a balance will not tip more in one direction than the other, when everything is equal on both sides, and in the same way all those who reason about morals and politics, with a view to discovering about human actions, tacitly make use of the same foundation, that there is always a reason or cause which inclines the will". PAR KIN SO N, 1973, p. 113.

8 Essa me parece uma conseqüência implausível da teoria de escolha de Leibniz: ainda que todas as alternativas sejam muito desejadas, segundo Leibniz não haverá escolha sem preferência. Talvez às vezes seja mais correto dizer que uma alternativa foi escolhida porque foi desejada, ainda que com a mesma intensidade que as outras, em vez de atribuir a escolha a uma preferência. Pense, por exemplo, na escolha de uma entre várias gar rafas de 0 nọnhha sobre a prateleira de um supermercado.

9 "If complete indifference is required for freedom, then there is scarcely ever a free act, since I think it hardly ever happens that everything on both sides is equal. For even if the reasons happen to be equal, the passions won't be. So why should we argue about circumstances that do not arise? I don't think examples can be found in which the will chooses - that is, where it arbitrarily breaks a deadlock by just choosing - because there is always some reason for choosing one alternative rather than the other". Essas sentenças de Leibniz foram escritas na margem de 'Possibilidade e Liberdade' ('Possibility and Freedom'), e foram 'traduzidas ou corrigidas' por Jonathan Bennett. 0 texto está disponível no seguinte site do Professor Bennett: www.earlymoderntexts.com. 0 ensaio 'Possibility and Freedom' também se encontra, segundo Bennett, em G.W. Leibniz, P hilosophical E ssays (organizado e traduzido por R oger Ariew e D aniel Garber), H ackett Publishing Company, Indiana,1989: 19-23.

10 o u seja, o 'experimento crucial' para uma decisão entre essas teorias de escolha é uma experiência que podemos descrever, usando uma expressão de Gilbert R yle, como "uncatchable".

11 Em T eodicéa §169, Leibniz critica Epicuro por sustentar que enunciados sobre o futuro não são nem verdadeiros nem falsos, e, portanto, por negar "o primeiro e maior princípio das verdades da razão, ele negou que to da asserção ou era verdadeira ou falsa" (R ESCH ER , 1991: 114). Seção $\$ 169$ da Teodicéia é indicada por Leibniz numa nota ao parágrafo 31 da M onadologia, que apresenta o princípio de contradição. É de se supor que Leibniz pensava, pelo menos quando escreveu a Teodicéia, que o princípio de razão suficiente fosse um corolário do princípio de contradição.

12 Veja C AR LIN , 2004, p. 366.

13 Teodicéia §288.Veja C AR LIN , 2004, p. 366.

doispontos, Curitiba, São C arlos, vol. 2, n. 1, p.123-133, outubro, 2005 
14 Parece, portanto, que há um excesso de determinanates da escolha de A dão: as condições anteriores à sua escolha, e a idéia completa de Adão.

15 "A parentemente", porque jamais podemos ter certeza que todos os fatores causalmente relevantes para um efeito foram considerados.

160 jogo de Landé é um bom exemplo. Alfred Landé, 'T he case for indeterminism'. In: HOOK, 1974.

17 Sobre tais explicações causais, John M ackie escreve: “... de acordo com nossa exposição, Q pode ser uma conseqüência causal de $P$ sem que $P$ seja causalmente suficiente para $Q$, ainda que dadas as circunstâncias. Isso é estranho, mas parece correto. ... . [Se] Jim, que é daltônico, e sua esposa, Alice, que não carrega nenhum gene de daltonismo, têm uma filha, Jane, que tem um filho,Tom, eTom é daltônico, então o daltonismo deTom é uma conseqüência causal do daltonismo de Jim; mas este somente legou a qual quer filho de Jane uma probabilidade de 0,5 de daltonismo". M ACKIE, 1974, p. 48.

18 Parece, portanto, que há um excesso de determinantes da escolha de Adão: as condições anteriores a sua escolha, e a idéia completa de A dão.

doispontos, Curitiba, São Carlos, vol. 2, n. 1, p.123-133, outubro, 2005 


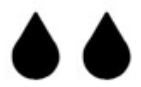

